\title{
Planar Integrated Magnetics (PIM) Module in Hybrid Bidirectional DC-DC Converter for Fuel Cell Application
}

Ouyang, Ziwei; Zhang, Zhe; Thomsen, Ole Cornelius; Andersen, Michael A. E.

Published in:

I E E E Transactions on Power Electronics

Link to article, DOI:

10.1109/TPEL.2011.2129598

Publication date:

2011

Link back to DTU Orbit

Citation (APA):

Ouyang, Z., Zhang, Z., Thomsen, O. C., \& Andersen, M. A. E. (2011). Planar Integrated Magnetics (PIM) Module in Hybrid Bidirectional DC-DC Converter for Fuel Cell Application. I E E E Transactions on Power Electronics. https://doi.org/10.1109/TPEL.2011.2129598

\section{General rights}

Copyright and moral rights for the publications made accessible in the public portal are retained by the authors and/or other copyright owners and it is a condition of accessing publications that users recognise and abide by the legal requirements associated with these rights.

- Users may download and print one copy of any publication from the public portal for the purpose of private study or research.

- You may not further distribute the material or use it for any profit-making activity or commercial gain

- You may freely distribute the URL identifying the publication in the public portal 


\title{
Planar Integrated Magnetics (PIM) Module in Hybrid
}

\section{Bidirectional DC-DC Converter for Fuel Cell Application}

\author{
Ziwei Ouyang, Student Member, IEEE, Zhe Zhang, Student Member, IEEE, Ole C. Thomsen, Member, IEEE, \\ and Michael A. E. Andersen, Member, IEEE, \\ Department of Electrical Engineering, \\ Technical University of Denmark,
}

Kgs. Lyngby, DK-2800, Denmark, zo@elektro.dtu.dk

\begin{abstract}
In most power electronics converters, the overall volume is mainly determined by the number of parts and the size of passive components. Integrated magnetics and planar magnetics techniques therefore have been an excellent option in order to reduce the counts and the size of magnetic components, hereby increasing the power density of converters. In this paper, a new planar integrated magnetics (PIM) module for a phase-shift plus duty cycle controlled hybrid bi-directional dc-dc converter is proposed, which assembles one boost inductor and two transformers into an E-I-E core geometry, reducing the number of parts, the total volume of converter, as well as the total core loss of the magnetic components. AC losses in the windings and leakage inductance of the transformers are kept low by interleaving the primary and secondary turns of the transformers. To verify the validity of the design approach and theoretical analysis, a lab prototype employing the PIM module is implemented for a fuel cell application with $20 \sim 40 \mathrm{~V}$ input voltage and $400 \mathrm{~V}$ output voltage. Detailed results from the experimental comparisons demonstrate that the PIM module is fully functional and electromagnetically equivalent to the discrete magnetics and a significant reduction of size can be achieved by using the PIM module.
\end{abstract}

Index Terms-- planar integrated magnetics, transformer, inductor, interleaving, hybrid, dc-dc converter and fuel cell.

\footnotetext{
Manuscript submitted August 31, 2010, revised November 23, 2010, accepted March 1, 2011. This work is supported by Flux A/S.

Parts of this paper have been presented at the conference IEEE Energy Conversion Congress and Exposition (ECCE) that has been be held in Atlanta,

USA, 2010.

The corresponding author Ziwei Ouyang, Ph.D student, is with the Department of Electrical Engineering, Technical University of Denmark, 2800

Kongens Lyngby, Denmark (e-mail: zo@elektro.dtu.dk).
} 


\section{INTRODUCTION}

In order to satisfy the requirements of modern power electronics application, magnetics integration with planar core has proven to be an effective means of reducing the converter size, the cost and increasing the converter efficiency [1]-[9]. Planar magnetics have unique advantages in terms of increased power density, better cooling capability, modularity and manufacturing simplicity as well as easy implementation of interleaved windings, which make them attractive for high current dc-dc power converter applications [10]-[12].

In recent years, most efforts in integrated magnetics (IM) focus on the current-doubler rectifier due to its suitability for low-output-voltage and high-output-current applications. Unlike conventional magnetic integration focusing only on core integration, both core and winding integration can be realized in the current-doubler rectifier design, causing lower conduction loss and core loss. As a result, lower overall cost, size as well as higher efficiency can be obtained by the IM design for the currentdoubler circuit [1]-[5]. A $1 \mathrm{~kW}$ with $300 \sim 400 \mathrm{~V}$ input voltage and $48 \mathrm{~V}$ output voltage asymmetrical half-bridge PWM converter (AHBC) employing an integrated $\mathrm{L}-\mathrm{L}-\mathrm{C}-\mathrm{T}$ module is constructed in [6]. Detailed suggestions are given of how one generic, integrated LCT component could be used to implement various resonant converter topologies by merely reconfiguring the external terminals of the integrated components [7]-[8]. An integrated transformer consisted of four step-down transformers wound on a single magnetic core for an interleaved four-phase forward converter has been proposed [13]. Coupled inductors can greatly reduce the steady-state inductor current ripples without compromising the transient response [14]-[18].

A new planar integrated magnetics (PIM) module for a phase-shift plus duty cycle controlled hybrid bi-directional dc-dc converter is proposed in this paper. One boost inductor and two transformers are integrated into an E-I-E core geometry. The modeling of the PIM structure is presented in Section III. The flux generated from each magnetic component assembled into the PIM module can be partially cancelled, resulting in a lower core loss. Integrated transformers in this geometry have higher magnetizing inductance compared to separated transformers in term of the same winding arrangements at the outer legs, reducing current stress. AC losses in the windings and leakage inductance of the 
transformers are kept low by interleaving the primary and secondary turns of the transformers. The design considerations for the PIM module are presented in depth in Section IV. Finally, in order to verify the validity of the design approach and theoretical analysis, a lab prototype employing the PIM module is implemented for a fuel cell application with $20 \sim 40 \mathrm{~V}$ input voltage and $400 \mathrm{~V}$ output voltage. Detailed results from the experimental comparisons demonstrate the PIM module is fully functional and electromagnetically equivalent to the discrete magnetics and a significant reduction of the size can be achieved by using the PIM module.

\section{Operation Principles Of The Hybrid Bi-Directional DC-DC CONVERTER}

Nowadays, the hybrid system based on fuel cells (FCs) and super-capacitors as an environmentally renewable energy system has been applied in many fields, such as hybrid electric vehicle, uninterruptible power supply and so on [19], [20]. Boost derived topologies are preferred in fuel cell applications due to their low input current ripple [21]. Fig.1 shows a novel phase-shift plus duty cycle controlled hybrid bi-directional dc-dc converter, which is originally proposed in [22]. The converter utilizes a boost-type input structure to limit the current ripple drawn from the FCs. For better understanding, Fig.2 shows equivalent circuits of the converter. Two transformers $T_{1}$ and $T_{2}$ are employed to associate with a half-bridge circuit (see Fig.2-b) and a full-bridge circuit (see Fig.2-a) respectively. Phase-shift technique is used in the converter since it can realize zero voltage switching (ZVS) for all switches without auxiliary switches. However, if the amplitude of input voltage is not matched with that of output voltage, the voltage on the phase-shift inductor $L_{2}$ consisting of the leakage inductance of the transformers on the secondary side and an auxiliary inductor becomes high, resulting in a higher current stress on all components. In order to operate in a wide input range, duty cycle control for $S_{3}$ and $S_{4}$ therefore can be used to reduce the current stress and conduction losses [23]-[27].

As shown in Fig. 1, a boost type half-bridge structure associated with the switches $S_{1}$ and $S_{2}$ operating at $50 \%$ duty cycle is located on the primary side of the transformer $T_{1}$. The super-capacitor bank crossing on the two series-connected capacitors, $C_{S C l}$ and $C_{S C 2}$, is connected on a variable low voltage DC bus as an auxiliary energy source. Bi-directional operation can be realized between the 


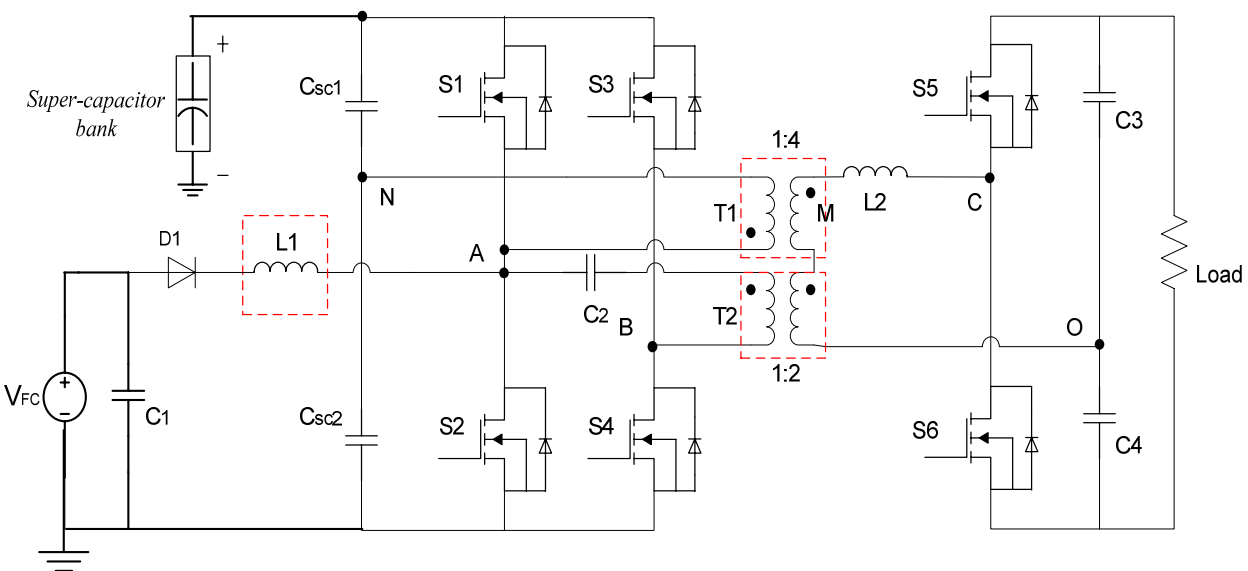

Fig. 1. Hybrid bidirectional dc-de converter topology.

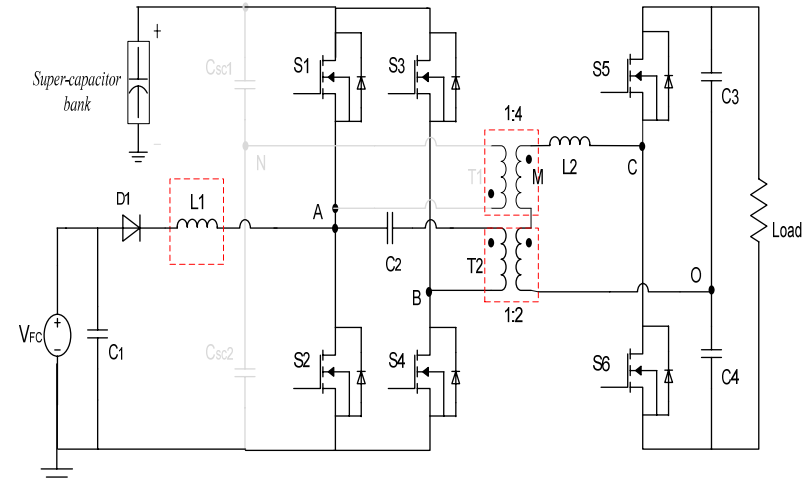

(a)

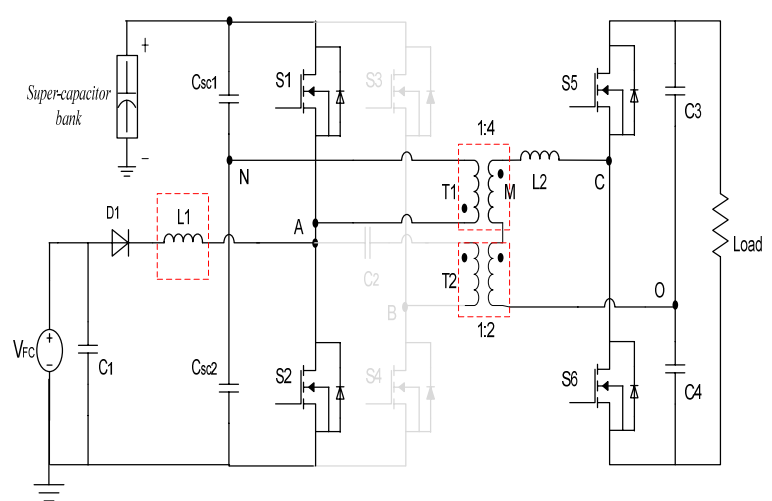

(b)

Fig. 2. Equivalent circuits of the converter. (a) full-bridge structure and (b) half-bridge structure.

super-capacitor bank and the output load. $S_{3}$ and $S_{4}$ are controlled by the duty cycle $D$ to reduce the current stress when the input voltage $V_{F C}$ is variable over a wide range. The two transformers, $T_{1}$ and $T_{2}$, with independent primary windings as well as series-connected secondary windings are utilized to realize galvanic isolation and boost a low input voltage to the high voltage secondary side. To avoid dc bias current of the transformer $T_{2}$ caused by asymmetrical operation in the full-bridge circuit (fluxwalking problem), a dc blocking capacitor $C_{2}$ is added in series with the primary winding of $T_{2}$. Voltage doubler circuit is used in the secondary side to further improve the voltage conversion ratio. The phaseshift inductor $L_{2}$ in the secondary side is utilized as power delivering interface element from low voltage input side to high voltage side. The delivered power is controlled by the phase-shift angle $\delta$ between $S_{I}$ and $S_{5}$, and can be expressed as (1) if the duty cycle $D$ is 0.5 [24].

$$
P=\frac{V_{C O} \cdot V_{M O} \cdot \delta \cdot(\pi-\delta)}{\omega \cdot \pi \cdot L_{2}}
$$

where $V_{M O}$ is the voltage on the secondary side of the transformers and $V_{C O}$ is the high side voltage as shown in Fig.1. To facilitate the explanation of the operation of the circuit in Fig. 1, Fig. 3 shows key 


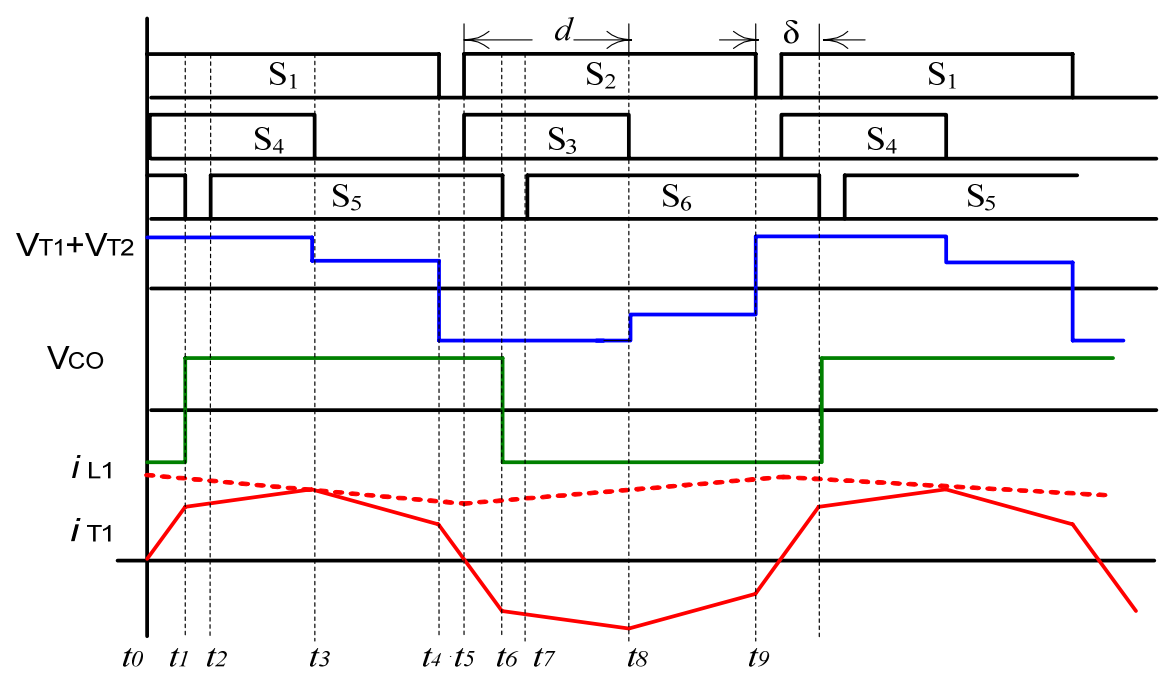

Fig. 3. Key waveforms of the converter under duty cycle control.

waveforms of the converter under duty cycle control. A simplified stage analysis during a half switching period is presented as follows,

1) Stage $1\left(t_{0}-t_{1}\right): S_{1}, S_{4}$ and $S_{6}$ are conducting. The voltage on $L_{2}$ is $V_{T 1 s}+V_{T 2 S}+V_{C O}$, so the $i_{L 2}$ will increase linearly. $I_{L 1}$ goes though the body-diode $D_{\mathrm{S} 1}$ of switch $S_{1}$;

2) Stage $2\left(t_{1}-t_{2}\right)$ : At $t_{1}, S_{6}$ is turned off. The inductor $L_{2}$ begins to resonate with the stray capacitors $C_{\mathrm{S} 5}$ and $C_{\mathrm{S} 6}$ of switches $S_{5}$ and $S_{6}$. When the voltage on $C_{\mathrm{S} 5}$ reduces to zero, the body-diode of $S_{5}$ starts to conduct, and the voltage $V_{C O}$ changes the direction. Hereby $V_{L 2}$ equals to $V_{T 1 s}+V_{T 2 s^{-}} V_{C O}$;

3) Stage $3\left(t_{2}-t_{3}\right)$ : At $t_{2}, S_{5}$ is turned on under ZVS. The current paths are the same as those in the stage 2;

4) Stage $4\left(t_{3}-t_{4}\right)$ : At $t_{3}, S_{4}$ is turned off. The inductor $L_{2}$ begins to resonate with the stray capacitors $C_{\mathrm{S} 3}$ and $C_{\mathrm{S} 4}$ of switches $S_{3}$ and $S_{4}$. When the voltage cross $S_{3}$ reduces to zero, $D_{\mathrm{S} 3}$ is therefore forward biased. The voltage crossing the primary winding of $T_{2}$ is clamped to zero. So $V_{L 2}$ equals to $V_{T 2 s^{-}} V_{C O}$;

5) Stage $5\left(t_{4}-t_{5}\right)$ : At $t_{4}, S_{1}$ is turned off. The inductor $L_{2}$ begins to resonate with the stray capacitors $C_{\mathrm{S} 1}$ and $C_{\mathrm{S} 2}$ of switches $S_{1}$ and $S_{2} . C_{\mathrm{S} 2}$ is discharged from $2 V_{F C}$. The rate of change depends on the magnitude $I_{T 1 p}+I_{T 2 p}-I_{L d c}$. At $t_{5}, V_{\mathrm{CS} 2}$ attempts to overshoot the negative rail. $D_{\mathrm{S} 2}$ is forward biased. During this period, $S_{2}$ can be turned on under ZVS.

After $t_{5}$, the same operational principles are repeated in the second half cycle. Detailed stage analysis and the characteristics of the converter can be referred in [22]. 


\section{NEW PIM Module STRuCTURE}

The conventional IM design currently uses soft-ferrite E-I or E-E core. In this work, a new PIM structure is proposed to integrate two transformers, $T_{1}$ and $T_{2}$, and boost inductor $L_{1}$ with a combined EI-E core geometry. The PIM module is shown in Fig.4. The windings of each transformer are symmetrically distributed into the outer legs of E-cores. The inductor, $L_{1}$, is constructed by two seriesconnected inductors wound in each center leg of E-cores respectively with certain air gaps. The middle I-core provides a low reluctance return path where flux cancellation can be achieved. Due to a high reluctance in the center legs, most alternating flux $\Phi_{1}$ and $\Phi_{2}$ generated from the transformer windings flows out of the center leg of E-core as shown in Fig.4-(b). The flux $\Phi_{3}$ generated from the inductor windings flows in the center legs of E-cores, and then distributes equally into the two outer legs. None of the flux $\Phi_{3}$ exists in the shared I-core. Half of $\Phi_{3}$ increases the total flux in the right side together with $\Phi_{1}$ and $\Phi_{2}$ and the other half of $\Phi_{3}$ decreases them in the left side at a certain instantaneous time. As a result, although the flux $\Phi_{3}$ couples with $\Phi_{1}$ and $\Phi_{2}$ on the two outer legs, the transformers' behavior will not be affected. Since partial ac flux cancellations are achieved in the core as well as smaller total ferrite volume, lower core loss might be obtained compared with discrete magnetics. However, notice that partial saturation may occur due to the flux overlapping on the right side leg, which limits the nominal power of the converter.

In term of this new geometry, many advantages can be concluded as below,

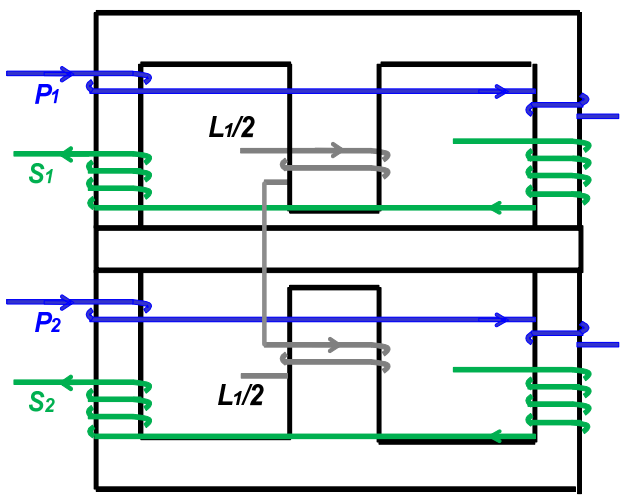

(a)

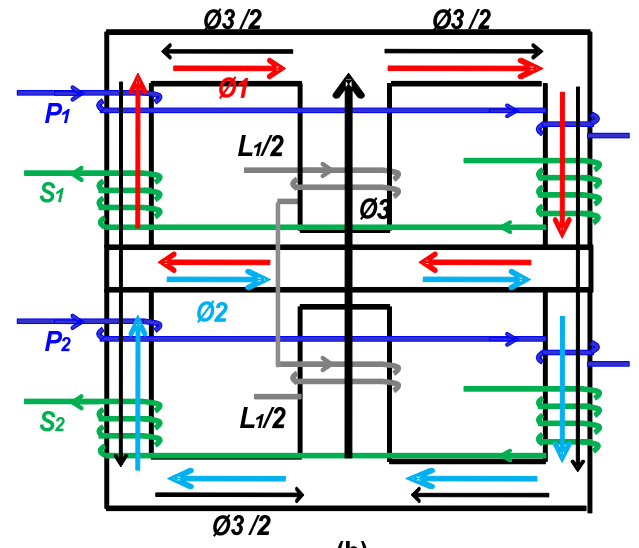

(b)

Fig. 4. Proposed E-I-E integrated magnetic structure (a) and its instantaneous flux distribution (b). 
(1) Air gaps located in the center legs cause a lower fringing effect as well as EMI problem compared with the case that air gaps located in the outer leg [1], [3]. Mechanically stabilization is also counted as an advantage.

(2) Magnetizing inductance will not be affected by the air gaps this is due to the fact that the flux $\Phi_{1}$ and $\Phi_{2}$ only circulate in the outer legs rather than the center legs with air gaps. Certainly, the magnetizing inductance in the PIM is much lower than the case where the same windings are wound on the center leg due to the equivalent cross section of the outer leg is only half of the center leg. However, magnetizing inductance can be improved by using the integrated approach compared to the separated transformers in term of the same winding locations. This is because the flux cancellation occurring in the shared I-core effectively reduces the length of the transformer flux path [28], [29]. It is mathematically proved in section IV and the measurement results in section $\mathrm{V}$ also demonstrate the same conclusion.

(3) Since partial ac flux cancellations are achieved in the core as well as smaller total ferrite volume, lower core loss might be obtained compared with discrete magnetics.

(4) Less number of cores is used, causing a lower cost for the converter.

(5) The integrated approach provides a low volume for the converter, which increases the power density required by space restrictions in automotive and integrated application.

(6) Flexibility. The integrated approach can be extended into many other topologies such as primaryparallel isolated boost converter [30], multi-transformers converters and so on.

\section{Magnetics Design Consideration}

\section{A. Primary Turns Factor}

If the duty cycle $D$ of $S_{3}$ and $S_{4}$ is smaller than $50 \%$ (duty-cycle control), it is impossible to obtain a complete flux cancellation in the shared I-core. A proper primary turns factor, $K=N_{l} / N_{2}$, should be chosen in order to minimize the core loss as well as maximize the delivered power capability. $N_{l}$ and $N_{2}$ are the number of turns on the primary side of $T_{1}$ and $T_{2}$ respectively. Fig.5 reflects the ac flux of the transformers, $\Phi_{1}$ and $\Phi_{2}$, and variation of flux in the shared I-core, $\Delta \Phi$, with different primary turns 


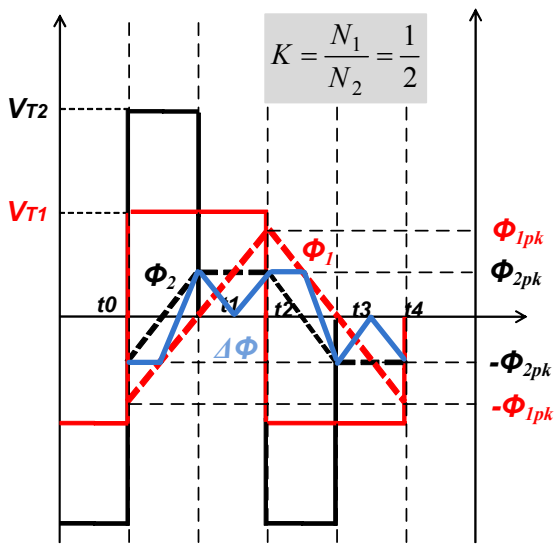

(a)

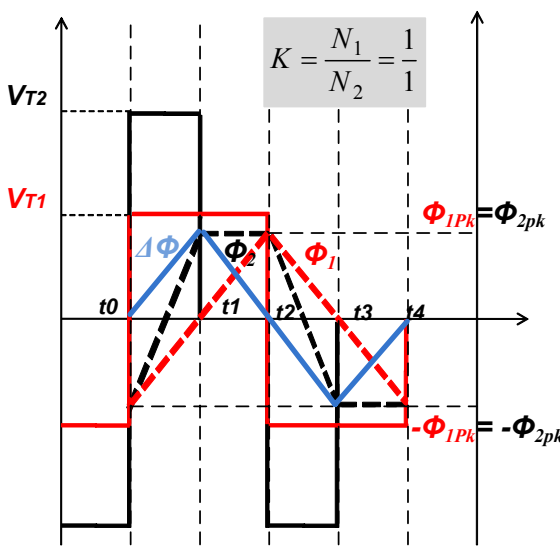

(b)

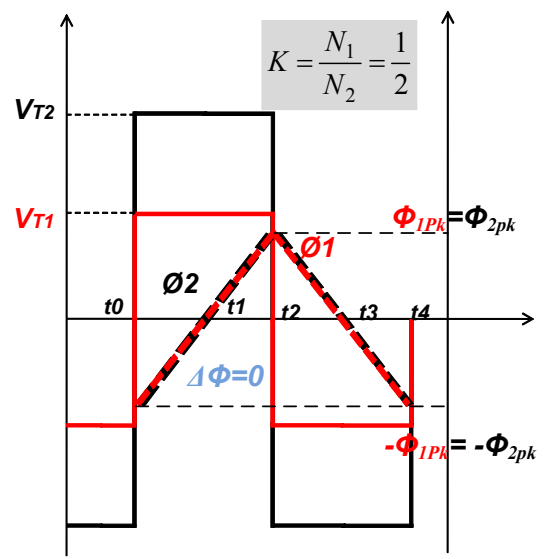

(c)

Fig. 5. Excitation voltages of the transformers and their ac flux waveforms when the primary turns factor is $K=0.5$ under duty cycle control (a); when the primary turns factor is $K=1$ under duty cycle control (b); when the primary turns factor is $K=0.5$ under non-duty-cycle control (c).

factors. Applying a piecewise linear model (PWL) to the non-sinusoidal waveform and combining this with the improved generalized Steinmetz equation (IGSE) [31] shows that the converter working under duty cycle control $(D<50 \%)$ has a lower core loss in the shared I-core when the primary turns factor is $K=0.5$; furthermore zero core loss (ideally) can be obtained in the shared I-core if the duty cycle $D$ is $50 \%$ (non-duty-cycle control).

\section{B. Magnetic Reluctance Model}

Fig.6 shows an equivalent magnetic model of the PIM module where $R_{1}$ is the reluctance of the outer leg of E-core, $R_{2}$ is the reluctance of I-core and $R_{C}$ represents the reluctance of the center leg of Ecore. $R_{C}$ is much bigger than $R_{1}$ and $R_{2}$ due to the air gaps in the center legs. Since the transformers and the inductor do not affect each other, the equivalent magnetic model can be divided into two parts as shown in the bottom of Fig.6. The left part represents the magnetic model associated with $T_{1}$ and $T_{2}$. The flux $\Phi_{1}$ and $\Phi_{2}$ will not flow in the center legs of E-core. The flux $\Phi_{1}$ and $\Phi_{2}$ in the shared I-core might be either partially or fully cancelled depending on the duty cycle $D$. The right part represents the magnetic model of the inductor $L_{l}$.

With assumption that leakage flux through the air is negligible, (2) (4) can be obtained according to the magnetic model,

$$
\begin{aligned}
& N_{1} \cdot i_{m 1}=\phi_{1} \cdot\left(2 R_{1}+R_{2}\right)+\left(\phi_{1}-\phi_{2}\right) \cdot R_{2} \\
& N_{2} \cdot i_{m_{2}}=\phi_{2} \cdot\left(2 R_{1}+R_{2}\right)+\left(\phi_{2}-\phi_{1}\right) \cdot R_{2}
\end{aligned}
$$




$$
N_{L} \cdot i_{L}=\phi_{3} \cdot 2 R_{c}+0.5 \cdot \phi_{3} \cdot\left(2 R_{1}+R_{2}\right)
$$

As seen in Fig.5, the rate of change on $\Phi_{1}$ and $\Phi_{2}$ are different over an entire period when the duty cycle

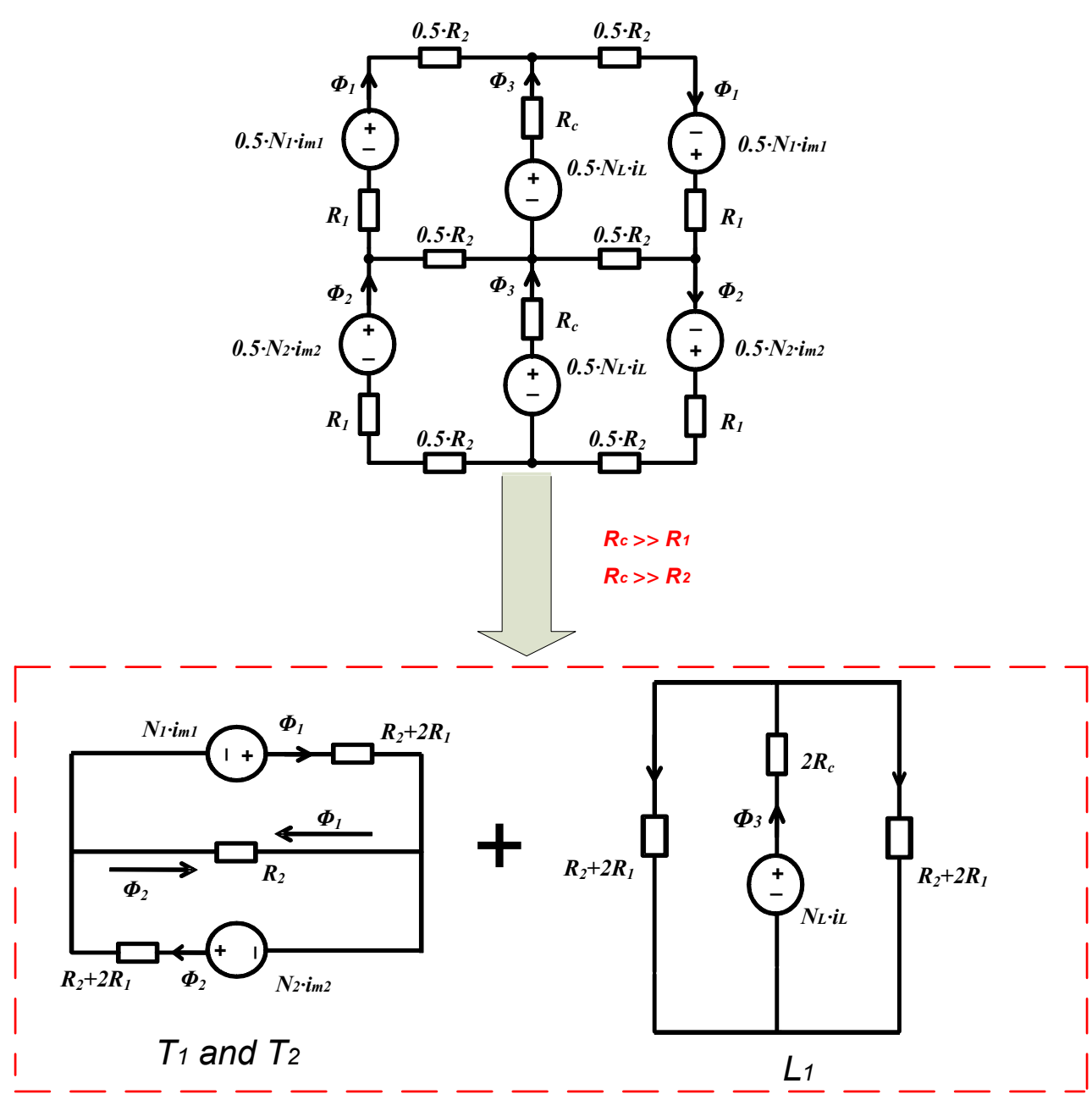

Fig. 6. Equivalent magnetic reluctance model of the PIM module.

control is used. Accordingly, the following two cases with four intervals are analyzed $(D<0.5, T$ is the period),

[1] Case $1[0 \sim D \cdot T]$ and $[0.5 \cdot T \sim(0.5+D) \cdot T]$ : the rate of change on $\Phi_{1}$ and $\Phi_{2}$ are the same. Based on Faraday's law, magnetizing inductances can be obtained,

$$
L_{m 1}=\frac{N_{1}^{2}}{2 R_{1}+R_{2}} ; \quad L_{m 2}=\frac{N_{2}^{2}}{2 R_{1}+R_{2}} ; \quad L_{1}=\frac{N_{L}^{2}}{2 R_{c}+R_{1}+0.5 \cdot R_{2}}
$$

[2] Case $2[D \cdot T \sim 0.5 \cdot T]$ and $[(0.5+D) \cdot T \sim T]:$ the rate of change on $\Phi_{2}$ is zero. Without excitation current on $T_{2}$ in this period, there is no sense in calculating the magnetizing inductance of $T_{2}$. 


$$
L_{m 1}=\frac{N_{1}^{2}}{2 \cdot\left(R_{1}+R_{2}\right)} ; \quad L_{1}=\frac{N_{L}^{2}}{2 R_{c}+R_{1}+0.5 \cdot R_{2}}
$$

For a single separated transformer with the same winding arrangement at the outer leg, the magnetizing inductance is equal to, $L_{m}=N^{2} / 2\left(R_{1}+R_{2}\right)$. As can be seen, such integrated transformers have higher magnetizing inductances than the single case when both $T_{1}$ and $T_{2}$ have excitation (case 1 ). This is because of the fact that the flux cancellation occurring in the shared I-core effectively reduces the length of the transformer flux path. Whereas, there is no improvement on magnetizing inductances if any one of the transformers has no excitation (case 2).

\section{Saturation Consideration}

It has been mentioned in the previous section that a saturation problem may appear due to the half of $\Phi_{3}$ (including dc component) and their overlapping flux together with $\Phi_{1}$ or $\Phi_{2}$ in the right part. According to Faraday's law and Ampere's law, the peak flux densities for each magnetic component in the PIM module can be derived,

$$
\begin{aligned}
& B_{p k_{-} T 1}=\frac{V_{F C}}{4 \cdot f \cdot N_{1} \cdot A_{e}} \\
& B_{p k_{-} T 2}=\frac{V_{F C} \cdot D}{f \cdot N_{2} \cdot A_{e}} \\
& B_{p k_{-} L}=\frac{\mu_{0} \cdot N_{L} \cdot I_{p k}}{l_{g}}
\end{aligned}
$$

where $f$ is the switching frequency and $A_{e}$ is the cross-section of the outer leg of E-core. $l_{g}$ is the total length of air gaps in the center legs of E-core. In order to avoid flux saturation in the PIM module, the following equations are required if $B_{p k_{-} T 2}$ is smaller than $B_{p k_{-} T 1}$,

$$
B_{p k_{-} T 1}+B_{p k_{-} L}=\frac{V_{F C}}{4 \cdot f \cdot N_{1} \cdot A_{e}}+\frac{\mu_{0} \cdot N_{L} \cdot I_{p k}}{l_{g}} \leq B_{s a t}
$$

Therefore, one of the drawbacks for the PIM module is a limited power capability. The power capability of the PIM module can be increased by minimizing the peak flux density of $T_{l}, B_{p k T 1}$, which can be implemented by increasing either the switching frequency or the number of turns. Although both methods might achieve lower core loss, increased switching frequency contributes to a higher eddy 
current effect in the conductors as well as higher switching loss, and also an increased number of turns will cause a higher winding loss.

The maximum allowed flux density ripple $\Delta B_{L}$ is given by the maximum peak flux density for the inductor $B_{p k_{-} L}$ and the ratio of allowed peak-to-peak ripple current $(\Delta l)$ to the peak current $\left(I_{p k}\right)$.

$$
\Delta B_{L}=B_{p k_{-} L} \cdot \frac{\Delta I}{I_{p k}}
$$

The flux density ripple shall be less than or equal to the maximum allowed value given by (9). Accordingly the required number of turns is

$$
N \geq \frac{V_{F C} \cdot T}{4 A_{e} \cdot B_{p k_{-} L}} \cdot \frac{I_{p k}}{\Delta I}
$$

High ripple current increases the core loss for the inductor $L_{1}$, and power loss in the MOSFETs. But low ripple current requires a high number of inductor turns, which results in high winding loss. Experience has shown that a good trade-off in high current application is a current ripple factor $\left(I_{p k} / \Delta I\right)$ of 2 to 3 .

\section{Winding Arrangement}

Winding losses in transformers increase dramatically with high frequency due to eddy current effects. Eddy current losses, including skin effect and proximity effect losses seriously impair the performance of transformers in high-frequency power conversion applications. Both the skin effect and the proximity effect cause the current density to be non-uniformly distributed in the cross-section of the conductor, and thus cause a higher winding resistance at higher frequency. The proximity effect loss, in a multilayer winding, may strongly dominate over the skin effect loss depending on the winding arrangement. Interleaving transformer windings can reduce the proximity loss significantly when the primary and secondary currents are in phase [32]-[34]. Fig.7 shows the winding arrangements and magneto motive force (MMF) distributions along a vertical direction for a half winding of $T_{1}$ and $T_{2}$ wound in one of the outer legs respectively. The value of $m$ [35] in each layer is equal to 1 which contributes to lower ac resistances. 


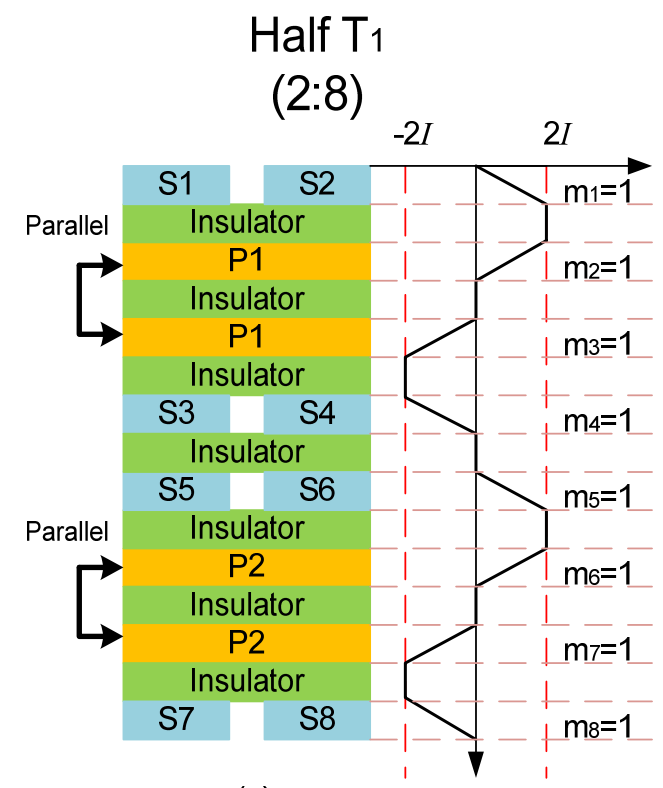

(a)

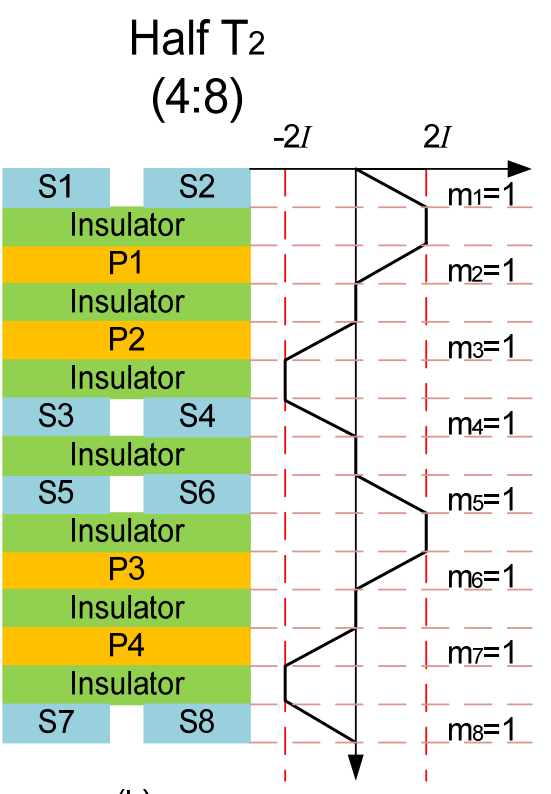

(b)

Fig. 7. Winding arrangements and magneto motive force (MMF) distributions for a half winding of $T_{l}$ wound in one of the outer legs (a) and for a half winding of $T_{2}$ in one of the outer legs (b).

Not only ac resistance can be reduced, but also leakage inductance can be significantly decreased by interleaving winding technique [36]. However, the reduced leakage inductance is not needed because the converter is working under phase-shift control, where a high leakage inductance is desirable. Considering a high current application, ac resistance is more important because it significantly affects the efficiency of the converter. Therefore the interleaving technique is still adopted in order to reduce ac resistance. An auxiliary inductor is added in series with the secondary windings to establish a desired phase-shift inductor $L_{2}$. Notice that interwinding capacitance in this kind of interleaving arrangement is much better than that in a full interleaving arrangement without compromising any other performances including leakage inductance and ac resistance because of fewer intersections between the primary and the secondary, contributing to a relative lower EMI problem [35].

\section{Simulation And EXPERIMENTAL ReSUlts}

The specification of the hybrid dc-dc converter is shown in Table I. The converter works with variable input voltage of $20 \sim 40 \mathrm{~V}$, and $400 \mathrm{~V}$ output voltage. The duty cycles of $S_{1}$ and $S_{2}$ is $50 \%$ to double input voltage to the DC bus of super-capacitor bank. The duty cycle control is used to reduce the peak currents. Switching frequency is $100 \mathrm{kHz}$. A series dc blocking capacitor $C_{2}$ accommodates any volt-second mismatching and flux walking problem in the full bridge circuit. The resonant circuit 
Table I

Specifications of the hybrid dc-dc converter

\begin{tabular}{|c|c|}
\hline Parameters & Values \\
\hline Input voltage $V_{F C}(\mathrm{~V})$ & $20-40$ \\
\hline Output voltage $V_{o}(\mathrm{~V})$ & 400 \\
\hline Duty cycle of $S_{1}, S_{2}$ and $S_{5}, S_{6}$ & 0.5 \\
\hline Duty cycle of $S_{3}$ and $S_{4}$ & $0.2-0.5$ \\
\hline Switching frequency $f_{s}(\mathrm{kHz})$ & 100 \\
\hline DC blocking capacitance $C_{2}(\mu \mathrm{F})$ & 10 \\
\hline Auxiliary inductor $L_{2}(\mu \mathrm{H})$ & 40 \\
\hline Boost inductor $L_{1}(\mu \mathrm{H})$ & 12 \\
\hline Turns ratio of $T_{1}$ & $1: 4$ \\
\hline Turns ratio of $T_{2}$ & $1: 2$ \\
\hline
\end{tabular}

consisting of $C_{2}$ and the primary leakage inductance of $T_{2}$ is designed to have a resonant frequency much lower than the switching frequency. A $40 \mu \mathrm{H}$ auxiliary inductor plus the leakage inductance obtained on the secondary side of transformers are utilized as the phase-shift inductor $L_{2}$, which determines the power as expressed in (1). A good choice for the value of the boost inductor $L_{1}$ is, as aforementioned to use a current ripple factor between 2 and 3.

To verify the validity of design approach, a 2D FEA simulation model linked with external simulation circuit has been built. The simulation parameters fully coincide with the specifications shown in Table I. Fig.8 shows an instantaneous distribution of the flux density, $B$, in the core.

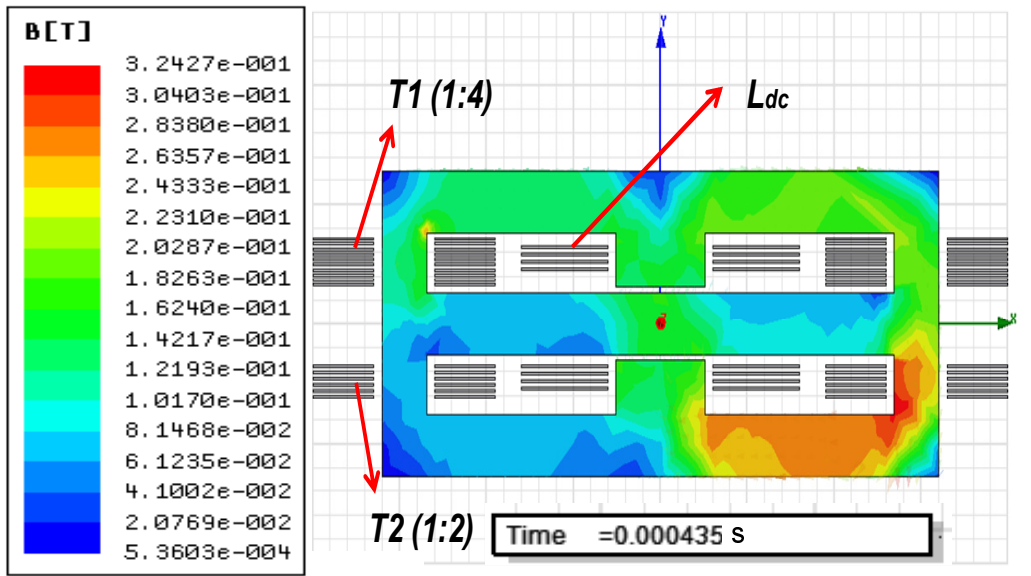

Fig. 8. Instantaneous flux density distribution in the core using 2D FEA simulation. 


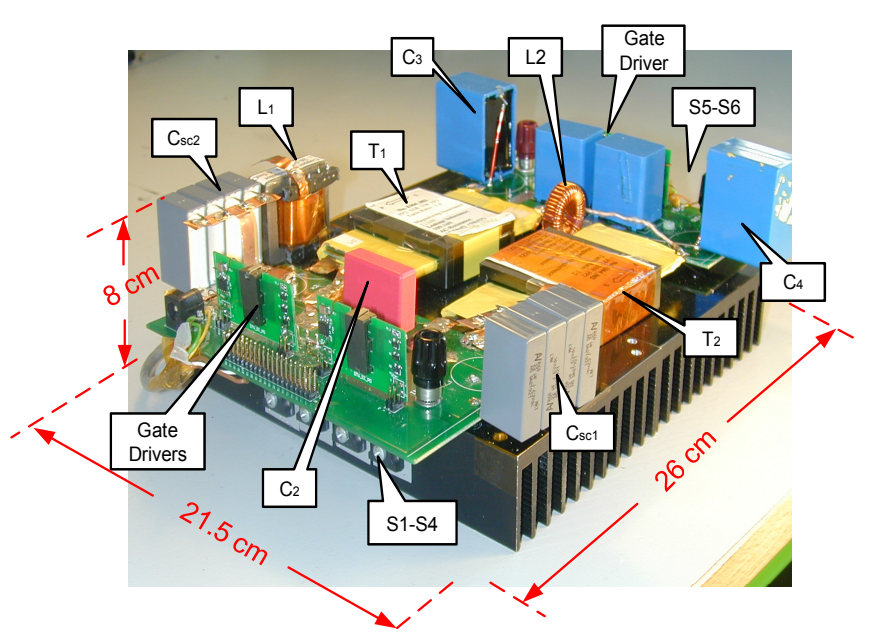

(a)

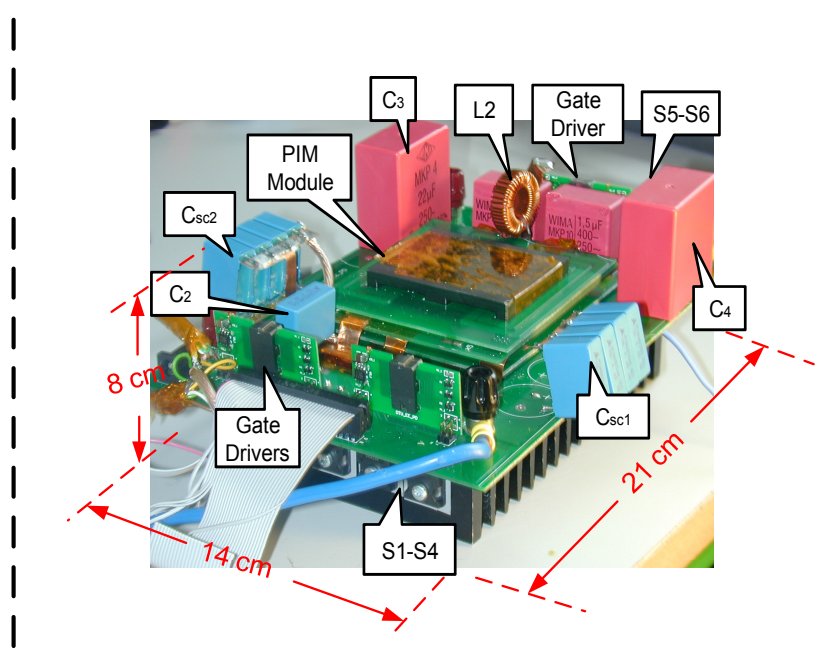

(b)

Fig. 9. (a) hybrid dc-dc converter with discrete magnetic components (b) hybrid dc-dc converter with proposed PIM module.

Apparently, the right part with a heavy color stress illustrates that half of $\Phi_{3}$ increases the total flux in the right side together with $\Phi_{1}$ and $\Phi_{2}$. Reversely, the other half of $\Phi_{3}$ decreases the flux in the left part. A partial flux cancellation on $\Phi_{1}$ and $\Phi_{2}$ occurs in the shared I-core and none of flux $\Phi_{3}$ goes through it.

The proposed PIM module is further validated by two experimental designs. Fig.9 shows pictures of lab prototypes with discrete magnetic components (a) and its integrated converter employing the PIM module (b) respectively. Accordingly, almost half size is achieved in the integrated converter. Primary switching MOSFETs $S_{1} \sim S_{4}$ are implemented by IRFP4568 and high voltage side MOSFETs $S_{5}$ and $S_{6}$ are realized by Vishay SIHG20N50C. In order to make a relative fair comparison, all switching devices, gate drivers, capacitors and auxiliary inductor are kept the same. In the integrated converter, the PIM module have 4 turns on the primary side of transformer $T_{1}$ and 8 turns on the primary side of $T_{2}$. The winding arrangements are shown in Fig.7. Two ELP-64 cores and one ILP-64 core all with N87 core material are used in the PIM module. The inductor $L_{l}$ has 4 turns and $0.5 \mathrm{~mm}$ air gap in both center legs of E-cores to form a $10 \mu \mathrm{H}$ inductance. All of windings are structured by a PCB with 4 oz copper thickness. In the discrete converter, all magnetic components are independent. The inductor $L_{l}$ is designed with a Kool-M $\mu-40 \mu$ core (distributed air gap core). 11 turns with $0.2 \mathrm{~mm}$ copper foil are wound in the $00 \mathrm{~K} 4020 \mathrm{E}$ core type to obtain the same inductance as the PIM module. Both $T_{1}$ and $T_{2}$ in the discrete converter use EILP-64 core types as well. Without the problem of limited power capability and flux cancellation, 4 turns therefore are used on the primary side of $T_{2}$. Interleaving technique is still 
used to reduce ac resistance. Notice that the transformer windings for the discrete converter are wound on the center legs of E-cores.

Table II

Measurement results for the discrete magnetics

\begin{tabular}{|c|c|}
\hline Parameters for the discrete magnetics & Values \\
\hline Leakage inductance of $T_{1}$ (ref. to pri.) & $101(n H)$ \\
\hline Magnetizing inductance of $T_{l}$ (ref. to pri.) & $236.6(u H)$ \\
\hline AC resistance of $T_{l}$ at $100 \mathrm{kHz}$ (ref. to pri.) & $22.1(m \Omega)$ \\
\hline Leakage inductance of $T_{2}$ (ref. to pri.) & $109.3(n H)$ \\
\hline Magnetizing inductance of $T_{2}$ (ref. to pri.) & $190.8(u H)$ \\
\hline AC resistance of $T_{2}$ at $100 \mathrm{kHz}$ (ref. to pri.) & $30.8(m \Omega)$ \\
\hline Inductance of $L_{1}$ & $13.1(u H)$ \\
\hline AC resistance of $L_{l}$ at $100 \mathrm{kHz}$ & $34.6(m \Omega)$ \\
\hline DC resistance of $L_{1}$ & $3.7(m \Omega)$ \\
\hline $\begin{array}{l}\text { Leakage inductance when the secondaries of the } \\
\text { two transformers are in series (ref. to sec.) }\end{array}$ & $1.9(u H)$ \\
\hline $\begin{array}{l}\text { Magnetizing inductance when the secondaries of } \\
\text { the two transformers are in series (ref. to sec.) }\end{array}$ & $4.6(m H)$ \\
\hline $\begin{array}{l}\mathrm{AC} \text { resistance at } 100 \mathrm{kHz} \text { when the secondaries of } \\
\text { the two transformers are in series (ref. to sec.) }\end{array}$ & $476.2(\mathrm{~m} \Omega)$ \\
\hline
\end{tabular}

Table III

Measurement results of the PIM module

\begin{tabular}{|c|c|}
\hline Parameters for the PIM module & Values \\
\hline $\begin{array}{c}\text { Inductance of } L_{l} \text { in the PIM Module } \\
\text { AC resistance of } L_{l} \text { in the PIM Module at } \\
100 \mathrm{kHz}\end{array}$ & $11.9(\mathrm{uH})$ \\
\hline $\begin{array}{c}\text { DC resistance of } L_{l} \text { in the PIM Module } \\
(\text { ref. to sec.) }\end{array}$ & $12.6(\mathrm{~m} \Omega)$ \\
\hline $\begin{array}{c}\text { Leakage inductance of the PIM Module } \\
\text { Magnetizing inductance of the PIM } \\
\text { Module (ref. to sec.) }\end{array}$ & $5.6(\mathrm{uH})$ \\
\hline $\begin{array}{c}\text { AC resistance at } 100 \mathrm{kHz} \text { of the PIM } \\
\text { Module }(\text { ref. } \text { to sec. })\end{array}$ & $535(\mathrm{~m} \Omega)$ \\
\hline
\end{tabular}

The measurement results on the magnetic components for both converters are shown in Table II and Table III respectively, obtained by an impedance analyzer PSM1735. As seen from the results, the 
PIM module has a higher leakage inductance which is due to the fact that the separated windings cause an imperfect coupling. Furthermore, the higher number of turns on $T_{2}$ also can be used to explain the higher leakage inductance [12]. With half cross-section of the center leg, magnetizing inductance in the PIM module is obviously smaller than that in the discrete magnetics. However, it is worth to notice that magnetizing inductance in the PIM module is higher than half of the one in the discrete magnetics, which coincides with the previous analysis in section III. $2.7 \mathrm{mH}$ magnetizing inductance referred to the secondary side is enough to be used in this application where only 0.44 A magnetizing current ripple is induced when the converter works in the nominal operation. With regard to ac resistance of the transformers, a longer winding length, higher number of turns on $T_{2}$ as well as a few fringing flux effects may cause a higher value in the PIM module. This contributes almost $1 \mathrm{~W}$ more of transformer winding loss than that in the discrete converter as shown in Table IV.

Table IV

Loss evaluation breakdown on the magnetic components for two different prototypes under $30 \mathrm{~V}$ input, $600 \mathrm{~W}$ output

\begin{tabular}{|c|c|c|c|c|c|}
\hline \multirow{2}{*}{ Loss } & \multicolumn{3}{|c|}{ Discrete Magnetics } & \multicolumn{2}{c|}{ PIM Module } \\
\cline { 2 - 5 } & $\mathrm{T}_{1}$ & $\mathrm{~T}_{2}$ & $\mathrm{~L}_{1}$ & $\mathrm{~T}_{1} \& \mathrm{~T}_{2}$ & $\mathrm{~L}_{1}$ \\
\hline \multirow{2}{*}{ Winding loss } & $4.33 \mathrm{~W}$ & $1.51 \mathrm{~W}$ & $2.16 \mathrm{~W}$ & $6.55 \mathrm{~W}$ & $6.49 \mathrm{~W}$ \\
\cline { 2 - 4 } & \multicolumn{2}{|c|}{ Total winding loss: $8 \mathrm{~W}$} & \multirow{2}{*}{ Total winding loss: $13.04 \mathrm{~W}$} \\
\hline \multirow{2}{*}{ Core loss } & $0.36 \mathrm{~W}$ & $0.91 \mathrm{~W}$ & $2.70 \mathrm{~W}$ & \multirow{2}{*}{ Total core loss: $1.73 \mathrm{~W}$} \\
\cline { 2 - 4 } & \multicolumn{2}{|c|}{ Total core loss: $3.97 \mathrm{~W}$} & \multirow{3}{*}{$11.97 \mathrm{~W}$} & \multicolumn{2}{c}{$14.77 \mathrm{~W}$} \\
\hline Total loss & \multicolumn{3}{|c|}{} \\
\hline
\end{tabular}

To facilitate a comparison of the efficiency of the two designs, the losses of major magnetic components are estimated. The results are tabulated in Table IV for the case when the input voltage is $30 \mathrm{~V}$ and the output power is $600 \mathrm{~W}$. Although $L_{1}$ in the discrete converter has a higher number of turns which causes a higher ratio of ac resistance to dc resistance due to the proximity effect, the winding loss of inductor $L_{1}$ in the discrete converter is much lower than that in the PIM integrated converter as indicated in the breakdown analysis. This is because a very low dc resistance can be obtained for $L_{l}$ in the discrete magnetics due to a thick and wide copper foil, and the dc loss dominates the winding losses of the inductor. The core loss is evaluated by calculating with the combination of the piecewise linear 
model (PWL) and the improved generalized Steinmetz equation (IGSE). The total core loss of the discrete magnetics is much higher than that of the PIM module. One reason is the distributed air gap core contributes a relative higher core loss in the discrete magnetics. The other reason is that the flux cancellation leads to a lower core loss. The authors would like to point out that the size, the winding loss, the core loss .etc are always in contradiction. A low core loss probably can also be realized in the discrete magnetics but the size and the winding loss might be compromised. In fact, a real fair comparison should be built on top of optimized magnetics design. In the present case, the comparison may not be real fair but it still shows that the PIM module has an advantage on core loss and has an impressive size deduction.

Fig.10, Fig.11 and Fig.12 show the measured waveforms in both the discrete converter (a) and the integrated converter (b) under duty cycle control at $30 \mathrm{~V}$ input voltage and $600 \mathrm{~W}$ output power. Fig. 10

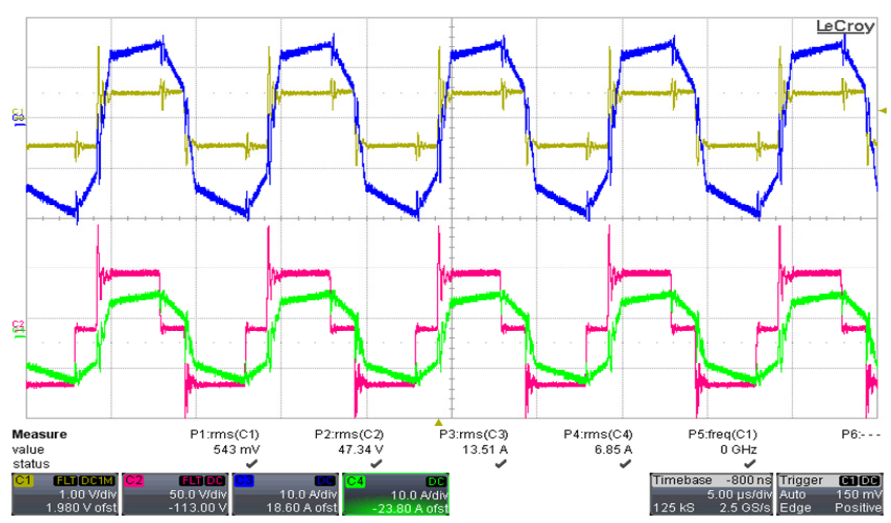

(a)

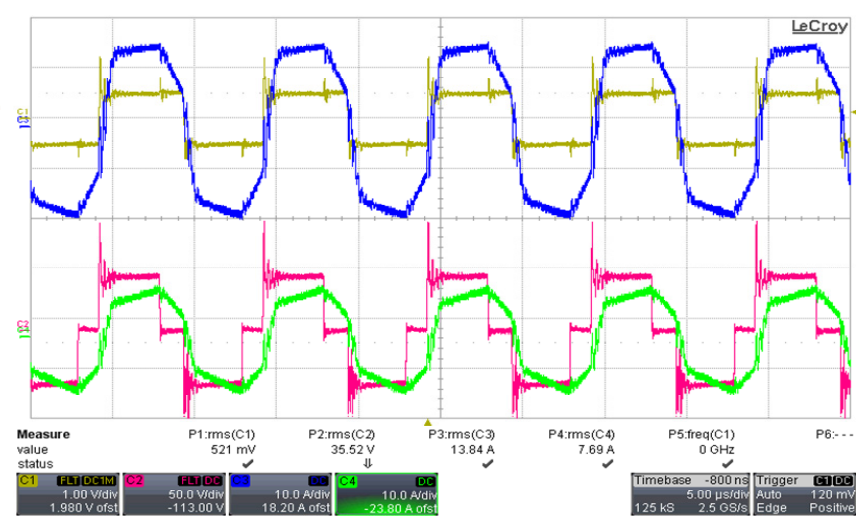

(b)

Fig. 10. Waveforms of the discrete converter (a) and the PIM converter (b), both are working under the duty cycle control at $30 \mathrm{~V}$ input voltage, $600 \mathrm{~W}$ output power. CH1: $\mathrm{V}_{\mathrm{AN}}(50 \mathrm{~V} / \mathrm{div}) ; \mathrm{CH} 2: \mathrm{V}_{\mathrm{AB}}(50 \mathrm{~V} / \mathrm{div}) ; \mathrm{CH} 3: \mathrm{i}_{\mathrm{T} 1}(10 \mathrm{~A} / \mathrm{div}) ; \mathrm{CH} 4: \mathrm{i}_{\mathrm{T} 2}(10 \mathrm{~A} / \mathrm{div})$.

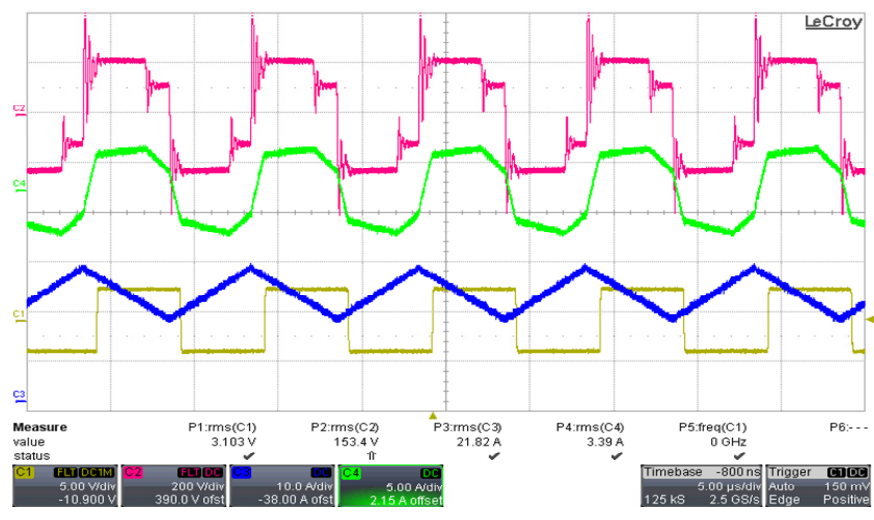

(a)

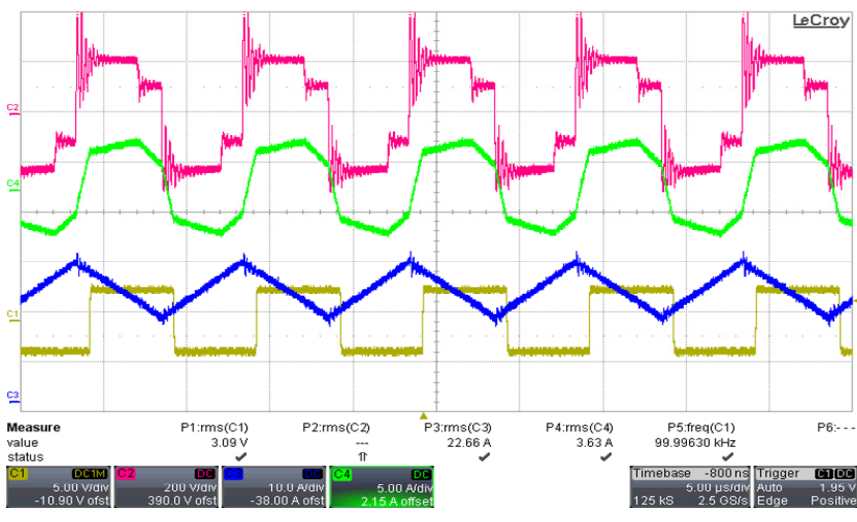

(b)

Fig. 11. Waveforms of the discrete converter (a) and the PIM converter (b), both are working under the duty cycle control at $30 \mathrm{~V}$ input voltage, $600 \mathrm{~W}$ output power. CH1: $\mathrm{V}_{\mathrm{CO}}(250 \mathrm{~V} / \mathrm{div}) ; \mathrm{CH} 2: \mathrm{V}_{\mathrm{MO}}(200 \mathrm{~V} / \mathrm{div}) ; \mathrm{CH} 3: \mathrm{i}_{\mathrm{L} 1}(10 \mathrm{~A} / \mathrm{div}) ; \mathrm{CH} 4: \mathrm{i}_{\mathrm{L} 2}(5 \mathrm{~A} / \mathrm{div})$. 


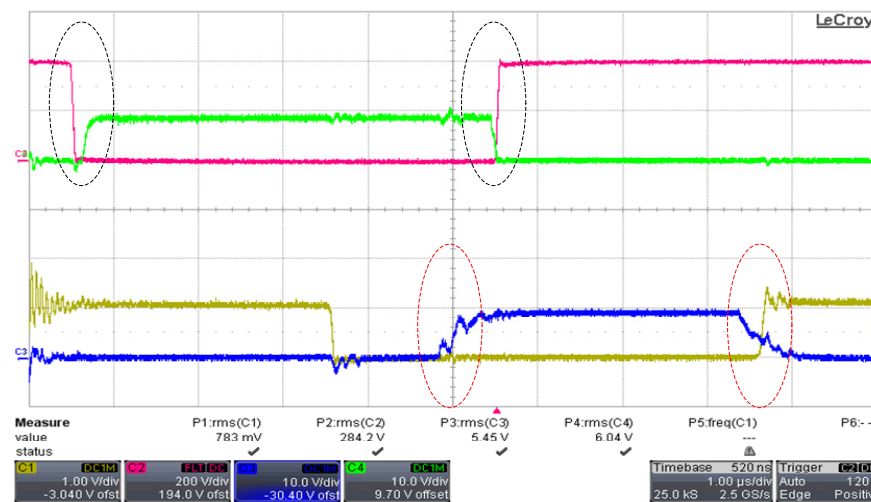

(a)

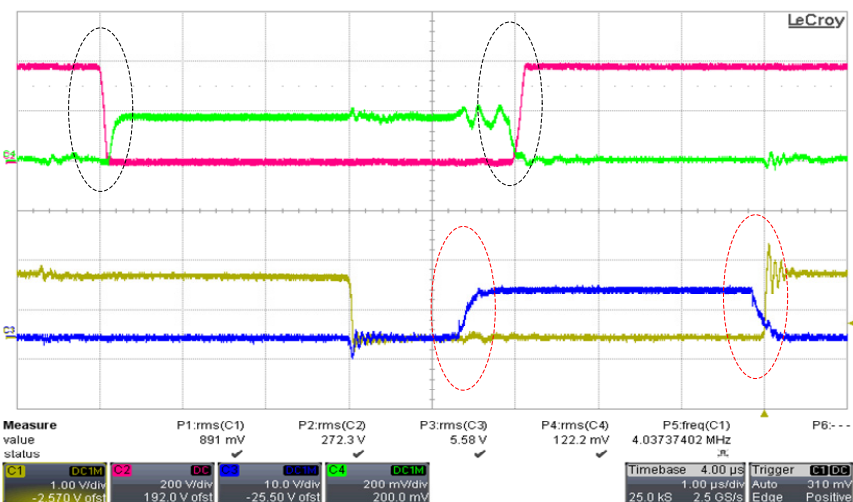

(b)

Fig. 12. ZVS waveforms of $\mathrm{S}_{4}$ and $\mathrm{S}_{6}$ for the discrete converter (a) and the PIM converter (b), both are working under the duty cycle control at $30 \mathrm{~V}$ input voltage, $600 \mathrm{~W}$ output power. CH1: $\mathrm{V}_{\mathrm{DS} 4}(50 \mathrm{~V} / \mathrm{div}) ; \mathrm{CH} 2: \mathrm{V}_{\mathrm{DS} 6}(200 \mathrm{~V} / \mathrm{div}) ; \mathrm{CH} 3: \mathrm{V}_{\mathrm{GS} 4}(10 \mathrm{~V} / \mathrm{div}) ; \mathrm{CH} 4: \mathrm{V}_{\mathrm{GS} 6}(10 \mathrm{~V} / \mathrm{div})$.

shows the plots of the primary voltages $\left(\mathrm{CH}_{1}: V_{A N}\right.$ and $\left.\mathrm{CH}_{2}: V_{A B}\right)$ and currents $\left(\mathrm{CH}_{3}: i_{T 1}\right.$ and $\left.\mathrm{CH}_{4}: i_{T 2}\right)$ for $T_{1}$ and $T_{2}$ respectively. As can be seen, the peak currents of the transformers have been dropped during the period of duty cycle control. Fig.11 shows the waveforms of the voltages $\left(\mathrm{CH}_{1}: V_{C O}\right.$ and $\mathrm{CH}_{2}$ : $\left.V_{M O}\right)$ on the secondary side and currents of the boost inductor $\left(\mathrm{CH}_{3}: i_{L 1}\right)$ and the auxiliary inductor $\left(\mathrm{CH}_{4}\right.$ : $\left.i_{L 2}\right)$. Zero-voltage turn on for the MOSFETs can be seen from Fig.12. For simplification, only $S_{4}$ and $S_{6}$ are chosen to demonstrate the ZVS waveforms. In fact, zero-voltage turn on for all of MOSFETs in the circuit can be achieved at this operating point. The waveforms illustrate that the PIM module is fully functional and electromagnetically equivalent to the discrete magnetics.

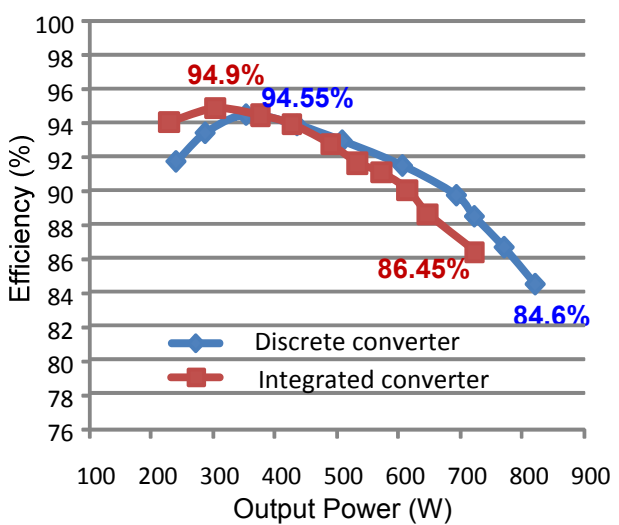

Fig. 13. Efficiency comparison between the discrete converter and the integrated converter under duty cycle control (35\%) at $30 \mathrm{~V}$ input voltage and $400 \mathrm{~V}$ output voltage.

High stability (<10 ppm) $0.1 \%$ shunt resistors and Agilent 34410A high precision multimeters are used for all efficiency measurements. Current sense signals are shielded and fitted with common mode filters. The comparison of efficiency curves between the discrete converter and the integrated converter 
is shown in Fig.13. The integrated converter has higher efficiency at light load than the discrete converter. This is due to the fact that the core loss dominates in the total power loss at light load. Oppositely, the winding loss dominates in the total power loss at heavy load. Therefore a higher efficiency in the discrete converter can be seen. The results coincide with the aforementioned analysis and the table breakdown.

\section{Conclusion}

A new integrated magnetics approach has been proposed in this work. Two transformers and one inductor are integrated into E-I-E core geometry to reduce the total volume of the converter, core loss and cost without compromising any electrical performance. The principle of the flux distribution in the core has been analyzed. Many advantages and disadvantages of the PIM module are included in the paper. Detail magnetics design consideration of the PIM module including primary turns factor, magnetic reluctance model, saturation problem and winding arrangement has been investigated in depth. Two converters with discrete magnetics and integrated magnetics (PIM module) have been built to demonstrate that the PIM module is fully functional and electromagnetically equivalent. The loss evaluation has illustrated that there is a core loss reduction in the PIM design. Furthermore, almost half the size of the discrete converter can be achieved in the integrated converter with the PIM module.

\section{REFERENCES}

[1] P. Xu, M. Ye, P. Wong and F. C. Lee, "Design of 48 V voltage regulator modules with a novel integrated magnetics," IEEE Trans. on Power Electron., vol.17, no.6, pp.990-998, Nov.2002.

[2] J. Sun, K. F. Webb, and V. Mehrotra, "Integrated magnetics for current-doubler rectifiers," IEEE Trans. on Power Electron., vol. 19, no. 3, pp.582-590, May, 2004.

[3] J. Sun, V. Mehrotra, “Orthogonal winding structures and design for planar integrated magnetics," IEEE Trans. on Ind. Electron., vol. 55, no. 3, pp.1463-1469, March, 2008.

[4] W. Chen, G. Hua, D. Sable and F. C. Lee, "Design of high efficiency, low profile, low voltage converter with integrated magnetics," in Proc. IEEE APEC, 1997, pp. 911-917.

[5] P. Xu, Q. Wu, P. Wong and F. C. Lee, “A novel integrated current doubler rectifier,” in Proc. IEEE APEC, 2000, pp. 735-740.

[6] R. Chen, S. J. T., van Wyk J.D. "Design of planar integrated passive module for zero-voltage-switched asymmetrical half-bridge PWM converter," IEEE Trans. on Ind. Appl., Vol. 39, no.36, pp.1648-1655, Nov.-Dec. 2003.

[7] P.A. J. van Rensburg, J.D. van Wyk and J.A. Ferreira, "Design, prototyping and assessment of a $3 \mathrm{~kW}$ integrated LCT component for development in various resonant converters," IET Power Electron., Vol. 2, no.5, pp.535-544, 2009. 
[8] J. T. Strydom, J. A. Ferreira, J. D. van Wyk, I. W. Hofsajer, E. Waffenschmidt, "Power electronic subassemblies with increased functionality based on planar sub-components," in Proc. IEEE PESC, 2000, pp. 1273-1278.

[9] M. J. Prieto, A. M. Pernía, J. M. Lopera, J. Á. Martínez, and F. Nuño, "Turn-Coupling in Thick-Film Integrated Magnetic Components for Power Converters," IEEE Trans. on Components and Packaging Technologies, vol.31, no.4, pp.837-848, Dec.2008.

[10]E. de Jong, J. Ferreira, P. Bauer, "Toward the next level of PCB usage in power electronic converters," IEEE Trans. on Power Electron., vol.23, no.6, pp.3153-3163, Nov. 2008.

[11]C. Quinn, K. Rinne, T. O'Donnell, M. Duffy, C.O. Mathuna, "A review of planar magnetic techniques and technologies," in Proc. IEEE APEC, 2001, pp. 1175-1183.

[12]C. Buccella, C. Cecati and F. de Monte, "A coupled electrothermal model for planar transformer temperature distribution computation" IEEE Trans. on Ind. Electron., Vol. 55, no.10, pp.3583-3590, Oct. 2008.

[13]L-P. Wong, Y-S. Lee, M. H. L. Chow, and D. K-W Cheng, "A four-phase forward converter using an integrated transformer," IEEE Trans. on Ind. Electron., vol. 55, no. 2, pp.817-831, March, 2008.

[14] S-Y Lee, A. G. Pfaelzer, and J. D. van Wyk, "Comparison of different designs of a 42-V/14-V de/dc converter regarding losses and thermal aspects" IEEE Trans. on Ind. Appl., vol.43, no.2, pp.520-530, Mar.2007.

[15]P-L. Wong, Q-Q. Wu, P. Xu, B. Yang and F. C. Lee, "Investigating coupling inductors in the interleaving QSW VRM," in Proc. IEEE APEC, 2000, pp. 973-978.

[16]H. Kosai, S. McNeal, B. Jordan, J. Scofield, B. Ray and Z. Turgut, "Coupled inductor characterization for a high performance interleaved boost converter," IEEE Trans. on Magn., vol.45, no.10, pp.4812-4815, Oct.2009.

[17]L. Yan and B. Lehman, "An integrated magnetic isolated two-inductor boost converter: analysis, design and experimentation” IEEE Trans. on Power Electron., vol.20, no.2, pp.332-342, Mar.2005.

[18]Z-W. Ouyang, O. C. Thomsen, M. A. E. Andersen, "New geometry integrated inductors in two-channel interleaved bidirectional converter," in Proc. IEEE IECON, 2010. pp. 582-586.

[19] A. Payman, S. Pierfederici and F. M. Tabar, "Energy management in a fuel cell/supercapacitor multisource/multiload electrical hybrid system," IEEE Trans. Power Electron., vol. 24, no. 12, pp. 2681-2691, 2009.

[20] W-S. Liu, J-F. Chen, T-J. Liang, R-L. Lin and C-H. Liu, "Analysis, design, and control of bidirectional cascaded configuration for a fuel cell hybrid power system," IEEE Trans. on Power Electron., vol.25, no.6, pp.1565-1575, June 2010 .

[21] M. Nymand, R. Tranberg, M. E. Madsen, U. K. Madawala and M. A. E. Andersen, "What is the best converter for low voltage fuel cell applications-A buck or boost," in Proc. IEEE IECON, 2009, pp. 959-964.

[22]Z. Zhang, O. C. Thomsen and M. A. E. Andersen, "Wide input voltage range bidirectional DC-DC converter for fuel cell and supercapacitor in UPS system," in Proc. IEEE PEDS, 2009, pp.706-711.

[23] D. Xu, C. Zhao and H. Feng, “A PWM plus phase-shift control bidirectional DC-DC converter,” IEEE Trans. on Power Electron., vol.19, no.3, pp.666-675, May.2004.

[24] J. Wang, F.Z. Peng, J.Anderson, A.Joesph and R. Buffenbarger, "Low cost fuel cell converter system for residential power generation," IEEE Trans. on Power Electron., Vol. 19, no.5, pp.1315-1322, Sep. 2004.

[25]Y. Jang and M.M. Jovanovic', “A new PWM ZVS full-bridge converter," IEEE Trans. on Power Electron., Vol. 22, no.3, pp.987-994, May. 2007.

[26]D. Liu and H. Li., "A ZVS bi-directional DC-DC converter for multiple energy storage elements," IEEE Trans. on Power Electron., Vol. 21, no.5, pp.1513-1517, Sept. 2006.

[27]H. Tao; A. Kotsopoulos, J.L. Duarte, M.A.M. Hendrix, “Transformer-coupled multiport ZVS bidirectional DC-DC converter with wide input range," IEEE Trans. on Power Electron., Vol. 23, no.2, pp.771-781, March. 2008. 
[28]Z-W. Ouyang, Z. Zhang, O. C. Thomsen, M. A. E. Andersen, O. Poulsen and T. Björklund, "Planar integrated magnetics design in wide input range dc-dc converter for fuel cell application," in Proc. IEEE ECCE, 2010. pp. 46114618.

[29] G. Sen, Z-W. Ouyang, O. C. Thomsen and M. A. E. Andersen, "A high efficient integrated planar transformer for primary-parallel isolated boost converters," in Proc. IEEE ECCE, 2010. pp. 4605-4610.

[30]Z-W. Ouyang, G. Sen, O. C. Thomsen, M. A. E. Andersen, “Fully integrated planar magnetics for primary-parallel isolated boost converter,” in Proc. IEEE APEC, 2011.

[31]K. Venkatachalam, C. R. Sullivan, T. Abdallah, and H. Tacca, "Accurate prediction of ferrite cores loss with nonsinusoidal waveforms using only Steinmetz parameters," in Proc. IEEE Workshop Comput. Power Electron., Jun. 34, 2002, pp. 36-41.

[32] J. Ferreira, "Improved analytical modeling of conductive losses in magnetic components," IEEE Trans. on Power Electron., vol. 9, no. 1, pp. 127-131, Jan. 1994.

[33] W. G. Hurley, E. Gath, J. G. Breslin, “Optimizing the AC resistance of multilayer transformer windings with arbitrary current waveforms," IEEE Trans. on Power Electron., vol.15, no.2, pp.369-376, Mar. 2008.

[34]X. Nan, C. R. Sullivan, "An improved calculation of proximity-effect loss in high-frequency windings of round conductors," in Proc. IEEE PESC, 2003, pp.853-860.

[35]Z-W. Ouyang, O. C. Thomsen and M. A. E. Andersen, "Optimal analysis and improved design of planar transformer in high power dc-dc converters" IEEE Trans. on Ind. Elec., 2011.

[36]Z-W. Ouyang, O. C. Thomsen and M. A. E. Andersen, “The analysis and comparison of leakage inductance in different winding arrangements for planar transformer,” in Proc. IEEE PEDS, 2009, pp. 1143 - 1148. 